DOI: $10.20472 / I A C .2018 .043 .040$

ILKIN SEYIDZADE

Szent Istvan University, Hungary

\title{
VIRTUAL WORLD BUSINESS MODELS AND TECHNOLOGIES, THEIR IMPLEMENTATION AND COMPARISON WITH REAL-WORLD BUSINESS MODELS
}

\begin{abstract}
:
By the emergence and development of the new technologies in economy, the level of competition raised several times faster than the previous periods. Companies are facing the challenge of diminishing the production costs on high quality goods by implementing the modern technology in production, management, marketing, sales and all the other fields of the product realization.

This paper is based on wide literature review and researched the latest virtual world business model tools, such as Virtual and Augmented Reality, the ways of using them in modern economy. I also investigated the patterns of different companies that applied for these technologies and their results.

I introduced the main features of virtual world, and explored major technology waves that are Augmented Reality, Virtual Reality, and USEMIR (Ubiquitous Sensory Mixed Reality). Under the concrete examples, monetization of the virtual world business models had been explained to the readers. The main direction of my essay was introducing the previous precedents of technology implementation in macroeconomic level, its gains, challenges and future perspectives.

Article revealed the strong relatedness between the Virtual World and Real-World Economies. It will be used on conducting surveys for first research. Moreover, readers can get the initial knowledge on the topic and the patterns that previously were investigated.
\end{abstract}

\section{Keywords:}

Innovation, Adaptation, Technology, New Economy, Technology and Competitiveness.

JEL Classification: 000, 030, 033 


\section{Introduction.}

One of the important methods of the product development is virtual prototyping. It has been involved before creating physical prototype to make the design by use of computer-aided design (CAD), computer-automated design (CAutoD) and computeraided engineering (CAE) software. In other words, virtual prototyping is used for the creation of geometrical forms and testing the level of fitness, functionality, and motions of them. For instance, Fisker Automotive used this prototyping for designing its plug-in hybrid to comply with the Federal Motor Vehicle Safety Standards, that requires the integrity of the fuel tank in a rear crash.

Virtual Reality and Augmented Reality are the main tools of Virtual Prototyping. VR is generated by computer in three-dimensional environment. In this environment, the product can be realistically represented in current time, and engineer can manipulate and interact the product. Nowadays almost all the immersive experiences are considered as VR. It is being designed either by using real-world, or synthetic content, or the combination of these two. In opposite to VR, AR enriches the user's view on the real world with virtual objects, which are placed at right time and position regarding the user's perspective (D. Ma, J. Gausemeier, X. Fan, M. Grafe). The elements in Augmented Reality are augmented by computer-generated inputs, such as sound, graphics, video, GPS data, etc.

\section{Methodology.}

First, I am going to present a short literature review on this topic and deliver the interesting findings of different scholars who have researched this field and introduced precious thoughts and future perspectives.

Later, I am going to introduce the main features of virtual world tools and their distinctions. Together with that, I plan to explore major technology waves that are Augmented Reality, Virtual Reality, and Ubiquitous Sensory Mixed Reality (USEMIR). This part will help the readers to discover the VR and AR for any company, regardless the industry. Under the concrete examples, I will reveal the industries where these technologies are being used or have potential to be utilized.

Moreover, to give a better description of the VR and AR technologies, I will research the historical development of these tools, and explain the maturity cycles.

Current market volume and forecasts for the future will also be investigated based on the reports of the organizations that are researching this field. Together with this, the readers will explore the investment possibilities and money sources for investment.

Later, under the concrete examples, monetization of the virtual world business models will be explained to the readers by using calculative and quantitative methods. I will not only work on proven business model concepts, but also try to bring new ideas. The main direction of my essay will be about introducing the previous precedents of technology implementation in micro and macroeconomic level, its gains, challenges and future 
perspectives. For giving a better picture of how Virtual World Economy works I will also research the production features in this economy.

In the end, summoning up researches I present the conclusion where readers are introduced the main findings of this paper.

\section{Literature review.}

As mentioned before, this topic is one of the most outstanding topics in an economic sphere and different academicians conducted researches on Virtual World and virtual technology tools. There are several informal and formal definitions for the virtual world. For instance, Raph Koster defines it like "a virtual world is a spatially based depiction of a persistent virtual environment, which can be experienced by numerous participants at once, who are represented within the space by avatars (Koster, 2004). Here, avatar is a kind of digital representation that has a skill to perform an action and is controlled by a human agent in a real time. There is a strong communication between the users of virtual space. It can't be stopped or paused and continues to exist even after the user leaves. Virtual world essences the interaction between the people that are always a part of an ecosystem. Summarizing, we can explain Mark W. Bell's explanation: "Virtual world is a synchronous, persistent network of people, represented as avatars, facilitated by networked computers" (Mark W. Bell "Toward a Definition of Virtual World", 2008).

David Zeltzer characterizes the virtual reality as a system that enables single or multiple users to move and react in a computer simulated environment. This world is created by mathematical models and computer programs (D. Zeltzer, N. Pioch, and W. Aviles "Training the Officer of the Deck", 1995).

Some other scholars are explaining the purposes that Virtual and Augmented Reality can be used for. Among these purposes they mention defense, medical, and surgical measures. The basis for virtual reality enduring in its growth for so long is due to its intricacy (Riva, Mantovani and Capidaville, 2007). These scientists have also discussed the benefits that schools can take from Virtual Reality.

Wiederhold brothers have also conducted a scientific research on VR/AR use in medicine, discussing the negative and positive sides of it. They think that the list of experiences that patient can choose is limited by the capacity of computer and willingness of the doctor. Thus, the patient's choice is more constrained in real life and that may be abusive. So, at one level VR can an instrument of torture, at another a powerful mean of education (Wiederhold and Wiederhold, 2005).

William R. Sherman and Alan B. Craig give the definition of 4 key elements of Virtual reality that are virtual world, immersion, sensory feedback and interactivity (William R. Sherman and Alan B. Craig, 2003).

\section{Main features of the Augmented and Virtual Reality.}

The main task of the virtual and augmented reality is not the separation of the end user from the real world and immersion in a virtual environment, but the creation of a platform for interactive interaction with the object of interest. One of the main advantages of the technology of augmented reality is that, it is possible to interact with a certain physical image in real time by means of a computer base. 
There are some basic characteristics and requirements necessary for the normal functioning of Virtual and Augmented Reality technologies. First of all, in one form or another, there must be a computational platform capable of creating conditions for interaction with a physical object. Another important element of the augmented reality systems is the display for displaying objects. If earlier the role of such elements was performed by monitors, which was customary for perception, today their role is played by complex physical systems and various special sensors.

The next important condition for the functioning of Augmented Reality technologies is the possibility of interactive input, changes in existing virtual conditions, the possibility of interpreting the object under study exactly in the form in which it is required. At the same time, the system should be understandable so that it can be used in various forms not only by professionals, but also by a broad mass of people.

In modern conditions, one more important requirement for effective work of augmented reality is the possibility of storing and exchanging data. To for a system or a specific technology to design an object, it must receive information about this object from some source. Today, instead of manually entering conditions and parameters, the Internet is being used, which allows the user to quickly get a huge amount of information on the desired object and perform an interactive exchange with the end user. With the development of broad access to the Internet, it became possible to use virtual and augmented reality technologies to create artificial intelligence for performing complex tasks. But today such systems are intended for studying by a narrow circle of professionals, they are at the stage of prototypes, but in the future, they can be widely applied.

Both technologies are expected to reshape the different industries in close future, and even today it is being intensively used in different spheres such as medicine, tourism, science, etc. in following ways:

Entertainment: Everyone who starts to engage in virtual and augmented reality, firstly gets interested in entertainment, games, video, 360 degrees.

Design: Designers increase the effectiveness of their work by using helmets of augmented and virtual reality. There are solutions that allow designers from different countries to simultaneously work with one object in real time, which increases the efficiency of the production process or model and solves communication problems. VRtechnologies can be used in prototyping and modeling, in production when assembling products.

Sport: An interesting case of using virtual reality is experienced in sport in the US: when an American football player prepares for the match, he wears a virtual reality helmet and simulates the start of the game and his position on the field. So, he gains experience and together with the trainer works out this or that strategy.

Military: One of the pioneers of the use of virtual and augmented reality has been the military industry. In a virtual world or with the help of augmented reality, it is possible to 
simulate fighting, demining or other operations to reduce the likelihood of an error in the actual environment.

Medicine: In this sphere, VR technologies are also beginning to be used more and more - starting from virtual training of physicians on how to operate correctly, to using virtual reality for the rehabilitation of patients and treating phobias (fear of heights, spiders and others). Immersion in virtual reality creates a presence effect that increases the effectiveness of rehabilitation/treatment. For example, nowadays some companies create a rehabilitation complex consisting of virtual reality mapping tools for partial and complete immersion, a motion capture system and feedback mechanisms. The complex is used to rehabilitate patients who have suffered a stroke and who need to restore their motor skills.

Service and control: Modern technologies of VR/AR allow implementing complex production control systems at enterprises. Particularly, this applies to cases where high accuracy is required. Computer systems can quickly find a deviating object, projecting on it pre-defined virtual parameters. In the long term, in this way, these technologies could be used to control complex communication systems (control of gas pipelines and other communications, rapid and effective detection and elimination of defects at nuclear power plants, roads).

Navigation: Issues of spatial orientation are among the most important and most rapidly developing in the structure of technologies of virtual and augmented reality. Modern systems allow you to accurately determine the position of the desired object in space, in an interactive form using mobile devices to display other additional information about the object. In combination with the development of the transport system, the technologies of augmented reality become extremely effective tools for performing applied tasks.

Tourism: The use of technologies of VR/AR in navigation and tourism is closely related to each other. Today, a person has the opportunity of finding the final destinations in advance, display the necessary reference information, and plan complex routes of travel. Being in a particular place, a person often does not need to go with the directory. It is enough to point the mobile device to the object of interest for more information.

Education: The technologies of virtual and augmented reality are very widely used in education as well. They allow you to quickly learn the necessary skills. Thanks to global systems, people have access to a huge layer of audiovisual information. Education becomes interactive, which allows the development of distance education without the constant inclusion of teaching staff. At the same time, it is already possible to talk about the use of technologies of VR/AR reality, starting with the junior school. Such integration leads to an accelerated development of the technologies under consideration with the goal of making learning even more accessible and comfortable $(\mathrm{H}$. Karimi, A. Hammad, 2014).

Purchases: In the future, with the help of augmented reality technologies, we can probably literally try clothes to the touch. Technology will allow us to remotely try on 
clothes, evaluate its texture. Recently, IBM introduced a system that facilitates the purchase process and most of the retail giants such as Adidas, Nike, Tommy Hilfiger started implementing those technologies. The main idea behind is, with the help of a special application, you can learn in advance important information about the purchased product.

Marketing: The VR/AR technologies allow performing complex 3D modeling, which can be widely used for the development of media and advertising. As an example, it becomes possible to project newspapers, magazines and other periodicals at various sites in the urban environment.

\section{The modern trend of virtual and augmented reality: cycle of technology maturity}

Virtual World tools have experienced several turns of development. We see now a new round in which virtual reality for the first time has a massive effect.

The revolution that we are now witnessing is the result of the appearance of the socalled "fourth platform".

The first platform - personal computers that appeared in the late 80's - early 90's, later came the internet, and the next stage was mobile technology. Today mobile consumption is more than the use of personal computers. Virtual and augmented reality is the next platform for which new markets, offers and business will be created. Now the very moment when it is needed to invest in VR / AR and develop technology in this area.

There is a hype cycle - a cycle or a curve of maturity of technologies, which was offered in 1995 by the research company Gartner ${ }^{1}$. Each technology on the market goes through a certain stage of this cycle.

The first stage is a "trigger", when nobody knows about the technology at the beginning of the path, only scientists and enthusiasts are engaged, and nobody invests in it.

The second stage is the "peak of excessive expectations." More and more people are learning about technology, the collective expectation of a boom, and a surge of interest in it is mounting. During this period in the mid-90's Nintendo released gadgets for virtual reality, but they were sold only 700 pieces. Quality content and resolution of existing screens was not enough to create a massive effect. Therefore, people became disappointed of the development of virtual reality in the early-mid 90 's and began to wait what would happen next. "Disappointment" is the third stage in the cycle of technology maturity. Now the augmented reality is in this stage.

Today the cycle of technology maturity of virtual reality is at the fourth stage, that can be called "education". In this stage solutions have already been found for the main problems of technology, and there is a lot of quality content and the audience. At the same time, VR is approaching the fifth stage - the "productivity plateau", when technology becomes ordinary, its use becomes routine. More and more people will use virtual reality in everyday life. One driver for the development of the VR market, so that

\footnotetext{
${ }^{1}$ Research and advisory company. www.gartner.com
} 
it has become truly massive will be the mobile VR. Samsung and Google put great hopes on it.

\section{Market volume and forecasts of different analytical reporting companies.}

Analysts at the International Data Corporation (IDC) $)^{2}$ predict that in the coming years the world industry of augmented and virtual realities will develop at a rapid pace.

The volume of AR/VR products globally and related services was estimated at about $\$ 14$ billion in the middle of 2017 . This year, this figure is projected to reach $\$ 27$ billion by the end of the year. In other words, the industry will show almost a twofold increase (plus 92\%).

In the following years, costs in the AR/VR-sphere will continue to increase rapidly. Analysts IDC believe that the average annual growth rate in compound interest (CAGR) in the period from 2017 to 2022 will be approximately $72 \%$.

According to IDC, taken by the segments, the largest category will be consumer products and services: the costs here will reach $\$ 53$ billion by 2022. The total of $\$ 56$ billion will go to the manufacturing and transport sectors, as well as the retail segment.

Moreover, last year, according to IDC, around 8.4 million sets of virtual and augmented reality of different types were sold around the world. This year it is expected to grow by $48.5 \%$, as result of which, shipments will reach 12.4 million units. Upon the research of $\mathrm{CCS}_{\text {Insight }}{ }^{3}$, total sales of devices of virtual and augmented reality this year will reach $\$ 1.8$ billion. Experts predict that by the end of the year manufacturers will be able to sell 22 million devices around the world. Most of them are still occupied by mobile headsets, like Samsung Galaxy Gear. However, true value for the market is represented by offline devices, such as HTC Vive Focus. By 2022, they will occupy a two-thirds of the market, the total amount of which is expected at $\$ 9.9$ billion.

It is projected that in 2018 approximately $90 \%$ of all implemented sets will be devices of virtual reality.

The analytical firm MarketsandMarkets ${ }^{4}$ has also released a forecast on the global development of the augmented reality market. In the period from 2016 to 2022, the world market growth reaches to $\$ 117.40$ billion at an average annual rate of growth, taking in account the compound interest at the level of $75.72 \%$. Of particular interest in the report is a comparison with the virtual reality market, which for the same time will grow to $\$ 33.90$ billion with an average annual growth of $57.84 \%$.

\footnotetext{
${ }^{2}$ Premier global provider of market intelligence, advisory services, and events for the information technology, telecommunications, and consumer technology markets. www.idc.com

3 Provider of reports, timely insights and information about future trends in technological industry. www.ccsinsight.com

${ }^{4}$ World's largest revenue impact company that delivers reports on various industry verticals. www.marketsandmarkets.com
} 
According to SuperData ${ }^{5}$, the growth of the audience of VR-content will gradually change the structure of the whole VR-market. Within two years, most of the market will be sales of VR-devices, but the share of services and software will grow and in 2020 for the first time surpass sales of equipment: $\$ 19.9$ billion against $\$ 17.8$ billion.

\section{Figure 1: Worldwide Virtual Revenue by Segment $(\$ B)$}

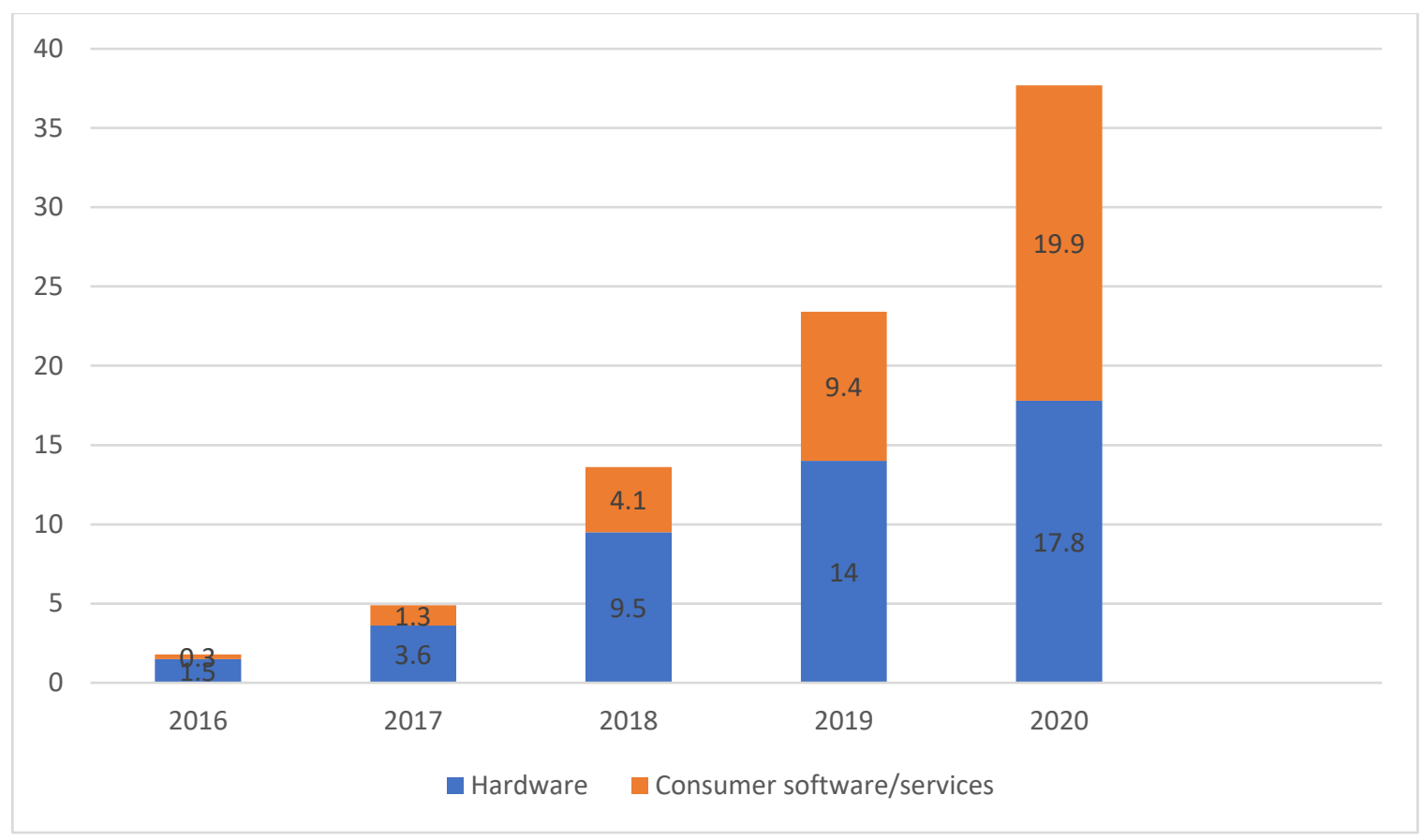

Source: SuperData Research VR Data Network

According to analytical estimates of Digi-Capital ${ }^{6}$, now the volume of the virtual and augmented reality market in the revenue from sales of content and devices is several billion dollars, but by 2020 will amount to more than $\$ 150$ billion. This is a huge opportunity for start-ups and investors. Now the main revenue is generated by helmets of virtual reality and the content that is created for them. But the picture will change - a big bet will be made on augmented reality. This can be seen from the diagram below.

\footnotetext{
${ }^{5}$ company that does Qualitative and Quantitative research on video game markets and spending habits of consumers.

${ }^{6}$ Silicon Valley based AR/VR adviser - reports, analytics, platform, strategy consulting, investment banking. www.digi-capital.com
} 


\section{Figure 2: Augmented/Virtual Revenue Forecast (\$B)}

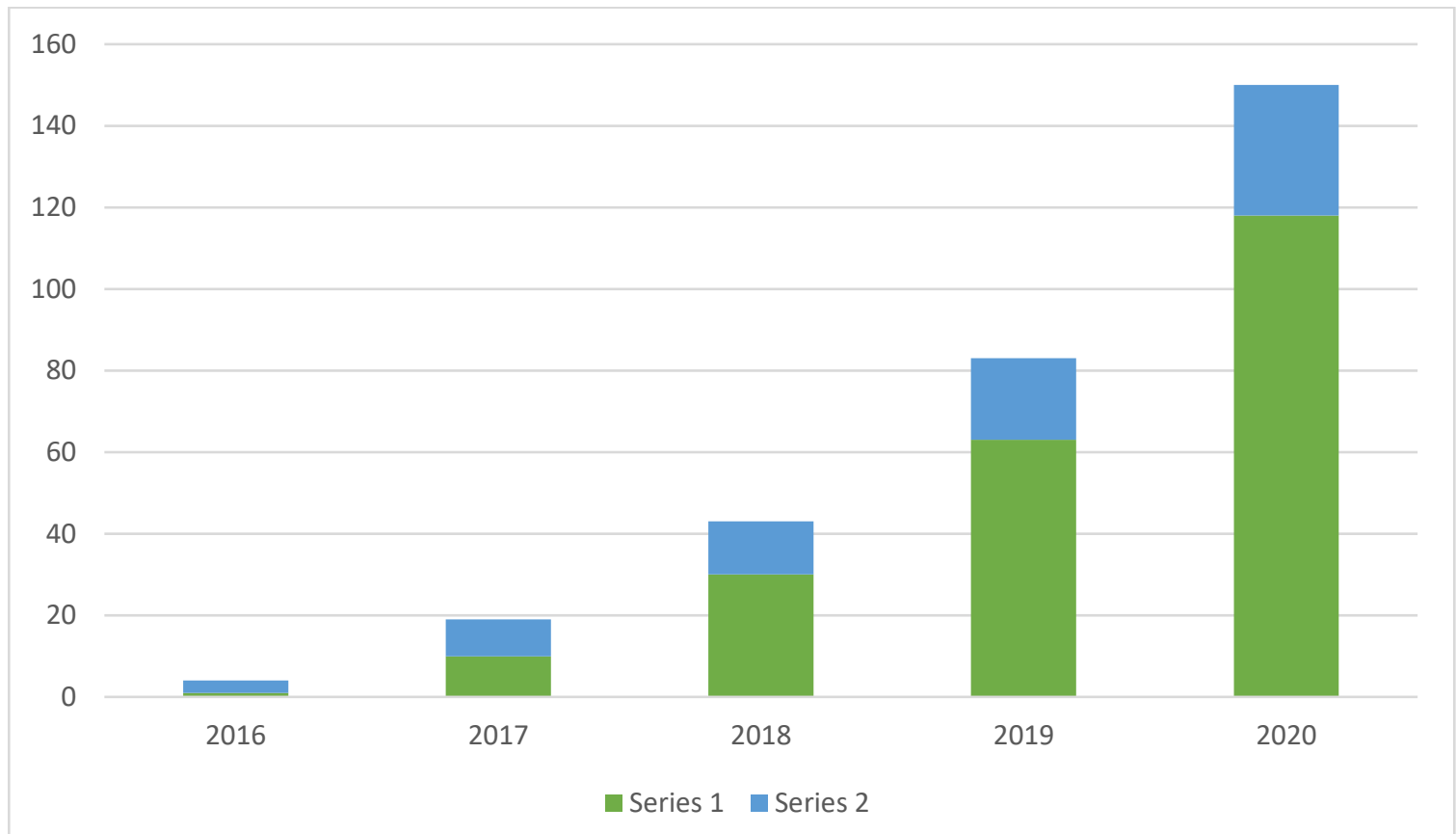

Source: www.digi-capital.com

The blue chart is the revenue from services, content and points that create an augmented reality. We see that the share of virtual reality in revenue is much lower, although it is the one who creates the main revenue.

The projected giant size of the market creates huge opportunities for creating the own business. An example of it can be Apple and their mobile applications: iPhone revolutionized the smartphone market. Who earned the most? Developers who began to make applications for smartphones. Since the application market was very small, the demand for them was large due to the distribution of these devices. Almost everything that came to hand was bought and downloaded. Most of these applications previously seemed generally impossible. Due to the large demand and small supply, an asymmetry was created on the market, on which smart people earned money.

\section{Investment to VR and AR and reasons for it.}

Investments in the industry are growing, and several peaks can be observed.

The first small peak: Facebook buys Oculus in the first quarter of 2014. The next jump occurs in the first quarter of 2016 - the peaks are largely due to investments in Magic Leap (it was invested by more than $\$ 1.5$ billion by Andreessen Horowitz, Kleiner Perkins, Google, JPMorgan, Fidelity, Alibaba). All major players moved into this field: Google, Apple, Samsung. Now this is not just an increase. Market players and analysts have confidence that this technology will occupy the future.

According to the researches of The Venture Reality Fund ${ }^{7}$, which tracks investments in virtual, augmented and mixed reality, in the first six months of 2017 , the volume of

\footnotetext{
${ }^{7}$ Venture fund investing in early-stage virtual, augmented and mixed reality startup companies
} 
investments in this sector grew by $79 \%$ compared to the same period last year. The report of the fund took in account data on 450 software companies, infrastructure, tools, platforms and applications. World investments in AR and VR, as indicated in the report, amounted to $\$ 2.3$ billion, and this is more than ever. The Fund predicts the continuation of this trend in the future. The growth of investments in the entertainment sphere AR / VR contributed to the company AMC, Disney, DreamWorks Animation, HBO, Netflix, Sony Pictures and Viacom. It is noticed that it is start-ups that basically move the sector forward, as they create profitable enterprises for specific sectors of the industry. It is also noted that tools and technologies for capturing reality attracted $56 \%$ more investment, and stereo displays - by $47 \%$. In the gaming sector, investment growth was $40 \%$, thanks to the technologies of the companies Oculus, Steam VR and PlayStation.

There are several reasons why companies intend to invest in this sector and they (mainly large companies) do it by buying projects in different ways:

- separate team for expertise: companies increase their spending on Research and Development (R\&D), and involve experts to start the projects from zero;

- uncompleted ideas to build own business: companies buy the start-up ideas and invest on it;

- products that increase the value of the hardware: mainly companies that intend to bring innovation for their hardware products invest on complementary technologies.

Mainly, the reason of the investment is an expected huge ROI. However, sometimes the reason may be the desire to "stake out" the market segment, as, for example, Google did with Google Glass. Or simply PR, when an investor buys a company that can do nothing further. In this case the start-up does not have a strategy, but nevertheless it is in the VR industry. The market is active from the point of view of purchases and will develop further.

\section{The source of the money in Virtual and Augmented Reality}

According to Digi-Capital's forecasts on the industry's income, a significant share of the expected revenue is accounted for by hardware and the content. These two areas are mainly divided VR/AR start-ups. The main advantages and disadvantages of each of the sides are listed below:

\section{Content:}

- Low entry threshold, but strongly depends on the niche.

- Entertaining content is a sphere in which mainly the beginners in the industry try themselves. But the main difficulty in developing games is that, it is difficult to predict success. It is like an unexpected roulette. Sometimes huge marketing and advertisement costs are involved to make the product popular.

- Cognitive content - the difficulty of the business model in this area is the fact that it is complicated to scale. 
- Educational content, - which really brings an effect, - is interesting for the investor. Especially in business-to-business (B2B), where the result of implementation for the business is easy to calculate.

\section{Hardware:}

- High capital intensity of R\&D and market entry (an example is the story of the Magic Leap with billions of investments in the absence of the product).

- The success of the product on crowdfunding platforms like Kickstarter and IndieGogo does not always anticipate the big demand in business-to-consumer (b2c): you can get to geeks and innovators, as it happened with Ouya. The company collected about $\$ 10$ million at Kickstarter, but eventually failed, including due to lack of mass of the target audience.

- Even under these conditions the predicted level of income with hardware is quite high.

\section{Production in Virtual Economy}

In his work called "The in-game economics of Ultima Online" (Zachary B. Simpson, 1999) professor Zachary B. Simpson reveals the two methods of production of new goods in virtual economy. The first method is almost same with the real-world economy: a user produces the raw material, makes a final good going through the different stages of the intermediate goods. The raw material production usually happens as a real-world production process, such as - mining. Nowadays, the term "mining" often refers to the cryptocurrencies, that are considered as a latest version of virtual currency. If there are different stages in the production period, it can be divided by the users. For instance, if a user is specialized in the production of intermediate goods, then another one specializes in the production of the final good.

The second method is slightly different from the real-world economy. In this method, user himself produces the final good directly. It is also mostly implemented in different games. User simply challenges another user by attacking him and the winner directly earn the appeared new good, that gets dropped by the entity.

Both methods of production we talked about, functions of five inputs ${ }^{8}$ :

Here, $L$ represents the number of hours that the user inputs in real world for producing one unit in virtual world. Users are completely free to control their time input.

$\mathrm{H}$ is a human capital input in real world, often refers to the user's efficiency in production. In other words, it represents the user's skills of producing new virtual items. The skills come from the time spent on learning process and the individual abilities.

There is also $A$, that is the virtual world human capital equivalent. This input is implemented differently in different virtual world. A user should learn a specific skill to

${ }^{8} \mathrm{q}=\mathrm{f}(\mathrm{L}, \mathrm{H}, \mathrm{A}, \mathrm{K}, \mathrm{R})$. 
perform a production task, and these tasks vary upon the worlds. Mainly, this learning process happens through the doing process. In other words, user just performs the same skill again and again several times before finally being efficient in it.

$\mathrm{K}$ represents a virtual physical capital input. Virtual physical capital is supposed to help the users in producing of new goods. For instance, if the user has better equipment and tools, they will be more efficient in the first production method, or if the user has better weaponry, he will be stronger in the second method.

$R$ is for the virtual resources that users can get. These resources are mostly endogenous.

Additionally, there is also third method of production, that is totally different from the previous two. As mentioned before, the previous two methods rely on the existing production process, or path, that had been designed by someone else. The users are not able to invent new goods, neither find another path. In some systems however, innovations can be made by the users. The can use their design and coding skills to implement something new into the existing system. This third method often relies on the non-game virtual worlds.

\section{Some macroeconomic indicators in virtual world}

Most of the macroeconomic indicators related to the virtual world have been examined by Edward Castranova in his paper called "Virtual Worlds: A first-hand account of market and society on the cyberian frontier" (Castranova, 2001). He researched the several trends, such as inflation, nominal wages, utility derived from the virtual property, etc. I will try to summarize his findings on these fields.

Castranova picked 29 different goods that are considered as different kinds of typical traded items and formed a price level index by tracking their prices. There is also a website where users report in-game market prices, and Castranova took the price data of the items from there. By equally weighing the prices of these goods he designed a price index and noticed that this index had fallen 29 percent in one year. That can be considered as a serious deflation.

Moreover, Castranova calculated an hourly wage in virtual world, ending up with USD 3.42. This number is almost more than USD 1000 of monthly salary.

When it comes to the utility derived from the virtual property, Castranove distinguishes 2 forms of the virtual property. One type is inherently scarce. For instance, in a graphical virtual world only particular number of objects can be located next to each other. Another type of the virtual property is artificially scarce due to the restrictions placed by the system.

According to Castranova, scarcity is the main thing that creates fun for the users in virtual world. He headlines that, the user's utility and well-being are constant. Utility rises with the additional avoidance of the constraints, and well-being increases the famousness of the world. In other words, the users mostly prefer the world with constraints than the one without them. Constraints are also divided into 2 forms: normal 
constraints and gaming constraints. Author indicates that removing the normal constraints may increase the utility, while releasing the gaming constraints may decrease. If to compare it to puzzles, in the beginning the utility from the puzzles increases as challenges are increased. So, small challenges are not desirable, but too hard challenges also negatively affect the well-being. Thus, in between of these two, optimum challenge can be found.

Conducting researches on the game called EverQuest, Castranova combined the different data collected from surveys and auctions, and formed the GNP per capita, where $\mathrm{V}_{\mathrm{t}}{ }^{9}$ is an indicator of total dollar value created in 1 year and $\mathrm{NC}$ is the number of the users. Each character in the game has a number, or level that indicates its position in the game, in other words, the higher the level is character, more efficient it is. So, $\mathrm{PI}$ represents the price for one-character lever. $\mathrm{H} 1$ stands for the number of hours the user uses on average for gaining a new level. Dividing the number of hours in a year $(\mathrm{Ha})$ with the average concurrent users, we get the annual created dollar value, or as Castranova says, GNP per capita. Comparing this number to the real-world economies, Castranova concluded that, EverQuest has the same GNP per capita as Russia, and it can be considered as 77 th richest country in the world.

\section{Virtual World and Virtual Economy in Micro and Macroeconomic level.}

As I headlined before, the Virtual World is a computer-based simulated environment populated by many people, who can simultaneously and independently explore the virtual world, participate in its activities and communicate with others. In other words, a user gets an access to the world that is simulated by computer and presents perceptual stimuli to the user. User in its turn can manipulate the different elements of this computer-stimulated world. This kind of presence sense may be away from the reality. There are also different ways of communication, text, icons, visual gestures, etc. Virtual World is a world, or economy where the game currencies trade against the U.S. dollars and involve more and more economists to work behind the scenes. A virtual economy is an emergent economy existing in a virtual world, usually exchanging virtual goods in the context of an Internet game.

According to Richard A. Bartle, virtual worlds are non-real spaces, implemented by a computer or a network of computers, meeting the following conditions (Bartle, 2006):

- There is a set of underlying, automated rules that dictate what its participants are able to do in it. These rules correspond to the physical rules of the real world.

- There is a distinct entity that represents a user and with which he strongly identifies. This entity is called the user's character or avatar. Interactions between the users, and between a user and the world take place via the characters.

- The interaction with and in the world, takes place in real time. The user's actions in the world receive (sufficiently) immediate response.

${ }^{9} \mathrm{~V}_{\mathrm{T}}=\mathrm{NC} \frac{\mathrm{PlHa}}{\mathrm{H} 1}=\mathrm{USD} 135$ million. 
- The world is shared, which means that there are multiple users in it, and that the users may interact with each other in the world.

- The world is persistent. When a user goes away the world does not, and events in the world, driven by other users, occur irrespective of any single user's presence. A persistent world exists independent of any single user.

The first virtual worlds appeared in 1970s as textual multiplayer games (multi-user dungeon). The users used to take part in this by reading the descriptions and writing the commands, that is why it was called "textual". Today's virtual worlds are much more impressive and well-designed than their predecessors.

Most of the modern virtual worlds have specially designed economic systems and these systems are supposed to be simulations of the real-world economies. The main indicators of these simulations are virtual currencies and markets. Game economy intends to influence the users by different encouraging activities, and creating the economic background is one of these activities. The users reportedly find the economic activities intriguing and adding to the immersion and the world-likeness experience of the virtual world (Burke 2002). There are five objectives that virtual economy should fulfill (Simpson, 1999):

- The economy rations power by limiting access to goods. The scarcity gives the more sense of real economy to the users.

- Allowing trade and supporting specialization;

- Through the cooperation and trade interaction should be granted;

- There should be goals set to acquiring more wealth;

- Economic role playing should be supported.

The patterns of the Virtual Economy are observed in Multi-User Dungeons (MUDs) and Massively Multi Player Online Role-playing Games (MMORPGs). The most significant connection between the real and virtual worlds has been observed in life simulation games, that nowadays is becoming the part of the marketing and production policies of most of the companies. Some aspects of economic interpretation laws are also valid for the virtual world. For instance, there is an online game, called "Second life". The game has about more than 1 million subscribers and regular users. The administration of the game recognizes the intellectual property rights policy for the assets created by the subscribers in game. Moreover, the virtual world has its own official currency, that is called Linden Dollars, and the "Second life" has its laissez-faire policy on the buying and selling the Linden Dollars for real dollars. Furthermore, there are some other games, where the real money can be used to do purchases in in-game shops.

According to Eyjolfur Gundmondsson - the world's first virtual world economist, the virtual economy is dealing with the same questions as the real economy does: what, when and for whom to produce? The prices in in-game economy are also regulated by the demand and supply law. However, there are some differences existing as well. There are some elements of the real world that are not valid for the virtual economy. According to the statistics, the average age rate in virtual world model is 27 and mainly settled by men. This kind of demographic difference sets the hardships in conducting 
real time economic experiments. Furthermore, in virtual economy the poverty does not exist, and it has less economic regulation than even the most liberal country in the world has. We all know that there is a huge of role the scarcity on the real-world economy. For instance, the neoclassical microeconomics, that is considered as a core concept of the examining of real markets, headlines the necessity of the scarcity concept, emphasizing that the resources are never enough for fulfill everyone's needs. Markets are needed as a mechanism of allocating the resources for people. Consequently, if there were unlimited resources, the markets would not be needed. In a virtual world, the marginal cost of production for most of the assets is zero, thus, everyone could have everything (Nash., Schneyer. 2004).

In a microeconomic level, this concept of scarcity seems to be the only difference between real and virtual world. However, let's take in account that in virtual games there would be no interest if there was no challenge of achieving or obtaining several assets or features. Even though those items are not scare as it is considered to mean in real world, it is still showing the signs of so called Veblen effect.

The main point of the Veblen effect is that, some things are valuable just because of its scarcity. For instance, the diamond ring is valuable, because it carries a feeling of exclusivity. If the diamond rings became abundant, it would stop being so expensive. Another example can be water, that is very necessary for the life on planet, but due to its abundancy, its price is not that high. Hence, some basic items in virtual world can be more expensive than its equivalent in real world, because in virtual world it is like diamond ring. Thus, concluding we may say that the microeconomic concepts can be used in examining the virtual markets. However, it is expected that the forms of demand curve will be unusual.

Real economy is mainly concerned by the good and service production. According to Popescu sisters (Popescu, Popescu, 2011), there are also some patterns in virtual economy, that are similar to the real economies, such as, labor, consumption, production, trade, etc. For instance, in simple games, it is easy to understand the main characteristics of the world economy from the mechanics existing in game. However, if the game is complex, it is hard to understand these characteristics by only analyzing the game characteristics, because this kind of analyze does not bring value added.

Apart from those patterns indicated above, there are also some other characteristics related to resources, that indicate the resemblance between virtual and real worlds.

- Rivalry - based to the game mechanics, the distribution of several resources within the game is limited for one or a small group of people;

- Persistence - upon the sessions that user spend time in virtual world the resources differently persists. Sometimes, these resources can be available for public view, even when the user is not logged in.

- Interconnectivity - the value of resource depends on the user's ability of using it to create some effect. These resources can affect the other people or be affected by them.

- Secondary market - virtual resources can be traded. The user can buy, sell or create any resource. Sometimes, these resources can be traded by real time assets - money. 
- Value added by users - by customizing and improving the resources each user can add value on the game.

Today the products of the virtual economy bring thousands and millions of dollars of revenue to different companies. As headlined before, it is not only about the online games, although the games are a big part of it. The big digital corporations, such as Facebook, Twitter, are considering the virtual world as markets, and these are the companies that are making billions of dollars revenue. The development of those markets led to the provision of income opportunities to the poor and low-income societies by supporting the local ICT infrastructure. However, it is still impossible to give the clear image of the any country's economy by using the indicators of the virtual world economy. In real economy, the better view of the real goods and services is calculated at constant dollar value and rise in prices measured by the Consumer Price Index and the Producers Price Index (Popescu, Popescu. 2011).

These patterns show that, virtual world can be a quite correct baseline, to learn and examine the real markets. When there is a hardship to obtain analytical solutions for the real economy problems virtual world economy can be used.

\section{Conclusion.}

As it is indicated in the paper, the use of the VR and AR technologies is being hugely increased over time and it is distributed in different fields of the real world. Due to flexibility and controllability of virtual environments, registration capabilities and effect immersions, such systems are widely used in various fields of science, education and engineering.

Nowadays, the requirements for the immersive functionality of the Virtual World prototyping tools are in a study level, where most of the big companies are in a rally for developing presenting the platform, upon which it will be widely accessible to everyone. These platforms should contain some basic characteristics, such as computational storage for interaction with a physical object, displays, possibility of interactive inputs, etc.

The cycles of development that Virtual World tools have experienced in last 3 decades, demonstrates us the historical changes that reshaped the VR and AR technology, and how it becomes a product of mass usage today. However, there is a difference between the cycles in which VR and AR technologies are. As it was mentioned, VR technology is on the stage, when the use of this technology becomes ordinary, while AR technology is in a "Disappointment" cycle, where the expectations of "something unreal and big" has not been fulfilled yet.

However, according to the different analytical and research companies' predictions the development of the VR and AR technologies will even fasten in the upcoming years. Both market value and costs on this field is showing an increasing trend and expected to rise enormously till the end of 2020. However, aside from the increasing tendency, some trends are expected to change. For instance, even though, since 2016 the main part of the market has been the sales of VR devices, due to growth of the audience of the VR market, it is expected that by 2020 share of services and software will surpass 
the devices/hardware. Moreover, the main interest is expected to shift towards the Augmented Reality, from Virtual Reality.

Considering the expected huge growth in this market, it became an ideal sector for the investments in terms of Revenue on Investment (ROI).

The investments on VR/AR market has experienced several peaks starting from 2014. According to the investigations, the main investments had been captured by VR tools and technologies. Moreover, the stereo displays and gaming industry had also been successful in investment involvement. Companies invest in the technology by different ways, such as increasing the costs on R\&D and creating an expertise team, buying the uncompleted ideas and developing them, increasing the value of the existing hardware.

The significant share of the income in this industry comes from the hardware and content. Each of them has advantages and disadvantages. For instance, content side has low entry threshold, and almost all the beginners in application development can try their luck. However, the expected the luck of the application is unpredictable, and it strongly depends on the niche. When it comes to hardware, market entry and R\&D requires high capital involvement. It is possible to find an investor for the developing of the idea, but it is still not guaranteed that, it will be successful. However, even under these conditions the predicted level of the income is quite high.

As mentioned before VR and AR technologies together create the economic existence, so-called "Virtual World". It is a computer-simulated world and occupied by different people from all over the world. In the beginning level, the needs of the Real World can be substituted by different elements of computer. For instance, text, icons, visual gestures (smile emoticons) can be used as a way of communication, or game currencies can be traded to real currencies. There are several conditions that shape the Virtual World.

There are two methods of production in Virtual Economy. One is the same as in the Real-World economy: after the raw material production, the production goes through different intermediate goods stages, before producing the final goods. However, the second method is slightly different from the real world. Here, the user produces the final good directly himself.

Most of the modern Virtual Worlds are based on the economies that are supposed to be the simulations of the Real-World Economy, which means, there are several patterns in Virtual World that can be considered as an alternative of the Real World. The examples could be the demand and supply law in the price regulation, and the main questions of economy: what, when and for whom to produce. Furthermore, we can add here the pattern of Veblen effect and labor, consumption, production, trade, etc.

However, there are some differences, such as demographic difference (Virtual World is mainly settled by men and the average age is 27 ), and the lack of poverty and scarcity in Virtual World. This kind of differences make the examining of the Virtual World markets difficult.

Investigation of these patterns can give as an ideal baseline for the examination of real world markets. 


\section{References}

Anon, CCS Insight. Available at: http://www.ccsinsight.com/.

Bartle, R.A., 2006. Designing virtual worlds, Berkeley, CA: New Riders.

Bell, M.W., 2008. Toward a Definition of "Virtual Worlds." "Virtual Worlds Research: Past, Present \& Future,"1.

Burke, R.R., 2002. Technology and the Customer Interface: What Consumers Want in the Physical and Virtual Store. Journal of the Academy of Marketing Science, 30(4), pp.411-432.

Castronova, E., 2001. Virtual worlds: a first-hand account of market and society on the cyberian frontier, Munich: Center for Economic Studies \& Ifo Institute for Economic Research.

Gartner_Inc, Fueling the Future of Business. Hype Cycle Research Methodology / Gartner Inc.Available at: http://www.gartner.com/.

Anon, IDC: The premier global market intelligence firm. IDC: The premier global market intelligence company. Available at: http://www.idc.com/.

Karimi, H.A. \& Hammad, A., 2004. Telegeoinformatics: location-based computing and services, Boca Raton, FL: CRC Press.

Anon, Know everything, everyone and get it done for AR/VR/XR. NEWS DigiCapital After mixed year mobile AR to drive 108 billion VRAR market by 2021 Comments. Available at: http://www.digicapital.com/.

Ma, D. et al., 2011. Virtual reality and augmented reality in industry the 2nd sino-German workshop, Berlin, Heidelberg: Springer Berlin Heidelberg.

MarketsandMarkets, http://www.marketsandmarkets.com/, Market Research Reports, Marketing Research Company, Business Research by MarketsandMarkets. Market Research Firm. Available at: http://www.marketsandmarkets.com/.

Nash, J. \& Schneyer, E. (2004). Virtual economies: An in-depth look at the virtual world of Final Fantasy $X I$ : Online. Unpublished manuscript, The Wharton School of the University of Pennsylvania. Retrieved July 1, 2004 from http://lgst.wharton.upenn.edu/hunterd/VirtualEconomies.pdf

Popescu, C.R., Popescu, V.A. \& Popescu, G.N., 2017. Forecasting Of Labour Market And Skill Needs In Nowadays Society - A Case Study On Romania'S Situation Facing The Challenges Of The New Economy. INTED2017 Proceedings.

Riva, G. et al., 2007. Affective Interactions Using Virtual Reality: The Link between Presence and Emotions. CyberPsychology \& Behavior, 10(1), pp.45-56.

Seiler, J., 2008. What Can Virtual-World Economists Tell Us about Real-World Economies? Scientific American. Available at: https://www.scientificamerican.com/article/virtual-world-economists-onreal-economies/.

Sherman, W.R. \& Craig, A.B., 2003. Understanding virtual reality: interface, application and design, San Francisco, Calif: Morgan Kaufmann.

Simpson, Z.B., The In-game Economics of "Ultima Online",

Wiederhold, B.K. \& Wiederhold, M.D., The Effect of Presence on Virtual Reality Treatment. Virtual reality therapy for anxiety disorders: Advances in evaluation and treatment., pp.77-86.

Zeltzer, D., Pioch, N.J. \& Aviles, W.A., 1995. Training the Officer of the Deck. IEEE Computer Graphics and Applications, 15(6), pp.6-9. 